Selective photoetching and transmission electron microscopy studies of defects in heteroepitaxial GaN

J. L. WeyherF. D. Tichelaar and H. W. ZandbergenL. Macht and P. R. Hageman

Citation: Journal of Applied Physics 90, 6105 (2001); doi: 10.1063/1.1416137

View online: http://dx.doi.org/10.1063/1.1416137

View Table of Contents: http://aip.scitation.org/toc/jap/90/12

Published by the American Institute of Physics

Publishing HORIzoNs

Small Conferences. BIG Ideas.

Applied Physics

Reviews

SAVE THE DATE!

3D Bioprinting: Physical and Chemical Processes

May 2-3, 2017 Winston Salem, NC, USA 


\title{
Selective photoetching and transmission electron microscopy studies of defects in heteroepitaxial GaN
}

\author{
J. L. Weyher ${ }^{\mathrm{a})}$ \\ Experimental Solid State Physics III, Research Institute for Materials, University of Nijmegen, \\ Toernooiveld 1, 6525 ED Nijmegen, The Netherlands and High Pressure Research Center, \\ Polish Academy of Sciences, Sokolowska 29/37, 01-142 Warsaw, Poland \\ F. D. Tichelaar and H. W. Zandbergen \\ National Center for High Resolution Electron Microscopy, Laboratory of Materials Science, \\ Delft University of Technology, Rotterdamseweg 137, 2628 AL Delft, The Netherlands \\ L. Macht and P. R. Hageman \\ Experimental Solid State Physics III, Research Institute for Materials, University of Nijmegen, \\ Toernooiveld 1, 6525 ED Nijmegen, The Netherlands
}

(Received 3 July 2001; accepted for publication 10 September 2001)

\begin{abstract}
Photoelectrochemical (PEC) etching has been used to study defects in heteroepitaxial GaN layers. In Ga-polar layers PEC etching reveals only dislocations in the form of filamentary etch features (whiskers). Transmission electron microscopy (TEM) confirmed a one-to-one correspondence between the whiskers and straight threading dislocations, which are mainly of edge and mixed type. In $\mathrm{N}$-polar layers, apart from dislocations, inversion domains (IDs) also give rise to the formation of more complex etch features that also have been confirmed by TEM. IDs of nanometer diameter result in formation of whiskers similar to the dislocation-related ones. However, when the diameter of IDs exceeds a critical size (about $100 \mathrm{~nm}$ ), crater-like deep etch features are formed during PEC etching. Based on the mechanism of PEC etching of $\mathrm{GaN}$ in aqueous $\mathrm{KOH}$ solutions, it is argued that inversion domain boundaries are electrically active defects. (C) 2001 American Institute of Physics. [DOI: 10.1063/1.1416137]
\end{abstract}

\section{INTRODUCTION}

Photoetching constitutes an attractive and ultrasensitive method of revealing chemical and crystallographic inhomogeneities in III-V semiconductors (see, e.g., Refs. 1-5). In contrast to the "orthodox" etching method, which results in formation of etch pits at the outcrops of dislocations, electroless photoetching (no external potential is used ${ }^{6}$ ) leads to the formation of nanometer-size protrusions on dislocations. The total morphology of the etch features depends, however, upon both the crystallographic and chemical nature of the defect, often assuming a complex shape. ${ }^{4,5}$ The mechanism of electroless etching, studied in detail in GaAs and $\mathrm{InP}^{3,6,7}$ involves multistep reactions taking place simultaneously at the semiconductor surface. These reactions are: reduction of oxidizing agent followed by injection of holes into the solid, oxidation of the solid using holes, and dissolution of the products. At defects (dislocations), recombination of charge carriers occurs, resulting in a local decrease of the etch rate. Interaction zones around crystallographic defects, which might contain dopant or impurity atoms and native defects, are revealed during photoetching either as hillocks or as depressions, depending upon the resultant electrical properties of the zones. ${ }^{4,5}$

Recently, it has been shown that photoelectrochemical (PEC) etching in dilute aqueous $\mathrm{KOH}$ solutions reveals dislocations in Ga-polar GaN heteroepitaxial layers in the form

a)Electronic mail: jlw@sci.kun.nl of whisker-like features. ${ }^{8,9}$ The association of the whiskers with dislocations was confirmed by means of transmission electron microscopy (TEM). ${ }^{8-10}$ Good correlation between the density of dislocations after PEC etching and the density of each pits formed in orthodox etchants (hot phosphoric acid, molten $\mathrm{KOH}$ ) has also been reported. ${ }^{11}$ PEC etching studies clearly showed that the mechanism of etching of GaN in aqueous $\mathrm{KOH}$ solutions is similar to the electroless one that operates during photoetching of other III-Vs, ${ }^{6}$ with the critical involvement of charge carriers. ${ }^{12-15}$ Therefore, it could be expected that the $\mathrm{KOH}+\mathrm{H}_{2} \mathrm{O}$ etching system is suitable for revealing the nonhomogeneous distribution of electrically active impurities in $\mathrm{GaN}$, no matter, whether they are gathered around dislocations or nonuniformly distributed in the matrix. Indeed, it has been shown recently that growth striations in GaN single crystals are visualized by electrochemical etching in $\mathrm{KOH}$ solution. ${ }^{16}$ In this article, results are presented on electroless PEC etching of heteroepitaxial $\mathrm{GaN}$ layers of $\mathrm{Ga}$ and $\mathrm{N}$ polarities that contain dislocations and inversion domains (IDs) as ascertained by TEM. The emphasis is on the interpretation of the mechanism of selective etching on defects and consequently, on their resultant electrical properties.

\section{EXPERIMENT}

The samples for our study were grown in-house by metal-organic chemical-vapor deposition (MOCVD) on sapphire substrates following the procedure described earlier. ${ }^{17}$ 

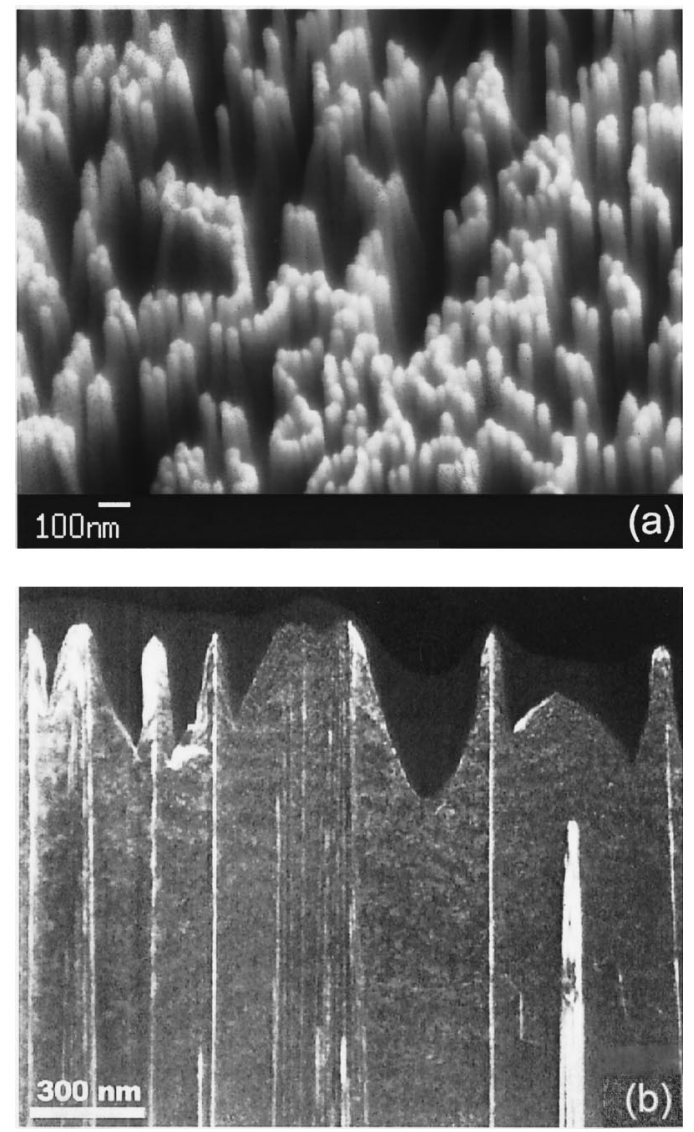

FIG. 1. (a) SEM image of dislocation-related PEC etched whiskers on the Ga-polar GaN heteroepitaxial layer. (b) Weak beam cross-sectional TEM image $(\sim g / 4 g$, with $g=[11-20])$ of PEC etched Ga-polar layer: one-toone correlation of dislocations to whiskers. Some dislocations end before reaching the top of whisker, indicating a foil cutoff by ion milling.

Standard Ga-polar GaN was grown on a 20 -nm-thick GaN buffer layer, while N-polar material was obtained without buffer by direct growth of $\mathrm{GaN}$ on sapphire. It should be remarked here that the calibration of PEC etching features observed on Ga-polar material by TEM has been already presented. ${ }^{8}$ However, in order to obtain a direct link between these results with that of PEC etching of N-polar material containing other types of defects, we will also briefly report

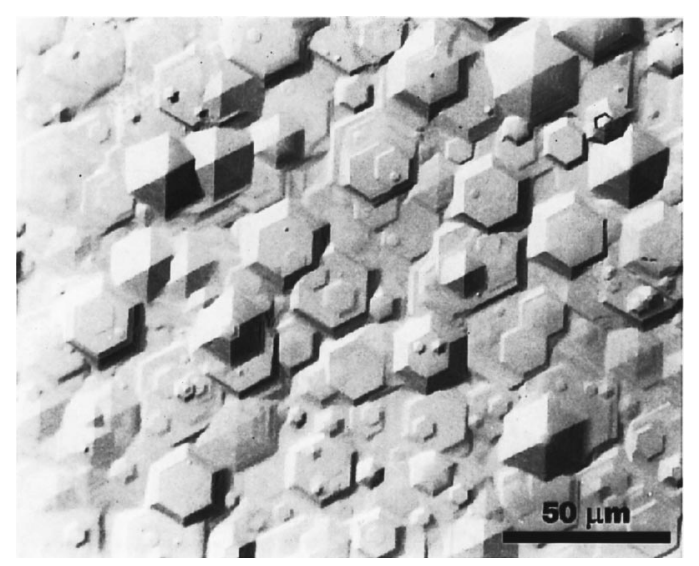

FIG. 2. DIC optical image of $\mathrm{N}$-polar GaN epitaxial layer grown by MOCVD on sapphire.

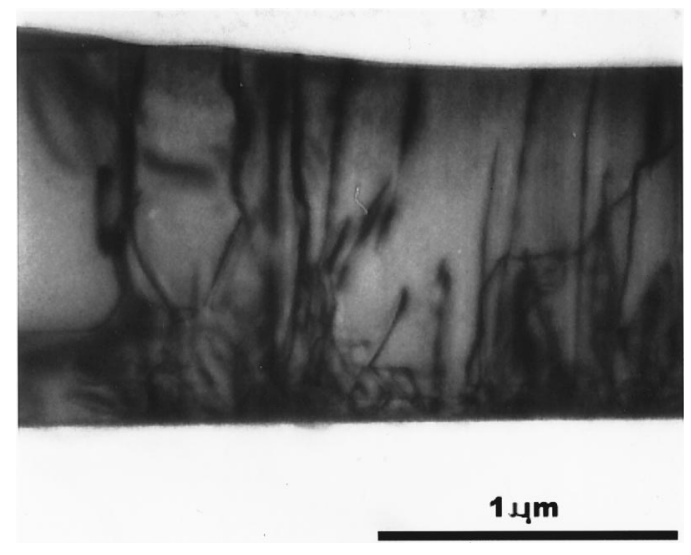

FIG. 3. Cross-sectional TEM image of an as-grown N-polar GaN heteroepitaxial layer from Fig. 2.

in this article on the PEC etching TEM calibration of Gapolar $\mathrm{GaN}$ as a reference material. The polarity assignment was based on the morphology of the epitaxial layers and was confirmed using chemical etching ${ }^{18}$ and quantitative electron diffraction. ${ }^{19}$ The samples were undoped with electron concentration $n=1.5 e 17 \mathrm{~cm}^{-3}$. PEC experiments were performed using the same setup as described by Youtsey, Adesida, and Bulman. ${ }^{12}$ PEC etching was performed using stirred $0.004 \mathrm{M} \mathrm{KOH}$ solution, Ti on GaN contacts, and 450 W Xe lamp illumination. The time of etching varied between 5 and $20 \mathrm{~min}$. Surface morphology before and after PEC etching was examined using differential interference contrast (DIC) optical microscopy and scanning electron microscopy (SEM). Structural defects and their association with surface features obtained during PEC etching were examined by conventional transmission electron microscopy and highresolution (HRTEM) imaging. Cross-sectional, electron transparent foils were prepared by the Ar-ion milling both from as-grown and PEC etched layers.

\section{RESULTS AND DISCUSSION}

The as-grown Ga-polar epitaxial layers were featureless under the DIC optical microscope. PEC etching resulted in formation of a dense pattern of straight whiskers, all about $50-60 \mathrm{~nm}$ in diameter, see Fig. 1(a). In order to confirm a correlation between the whiskers and dislocations, another sample from the same $2 \mathrm{in.}$ MOCVD wafer was photoetched in a short, 5 min run. This prcedure was used to avoid a possible breaking of long whiskers during preparation of cross-sectional TEM specimens. Detailed examination of large-area transparent foils led to the conclusion that all whisker-like features observed after PEC were formed on the outcrops of dislocations, as can be seen in Fig. 1(b). The vast majority of the dislocations in the Ga-polar samples are straight and threading across the whole thickness of the layer. They have either pure edge $(b=\langle 11-20\rangle / 3)$ or mixed $(b=\langle 11-23\rangle / 3)$ character. The results of this analysis are in agreement with data published earlier. ${ }^{8}$ Both findings do not exclude the possibility of formation of whiskers on screwtype dislocations; they show only the absence of these dislo- 


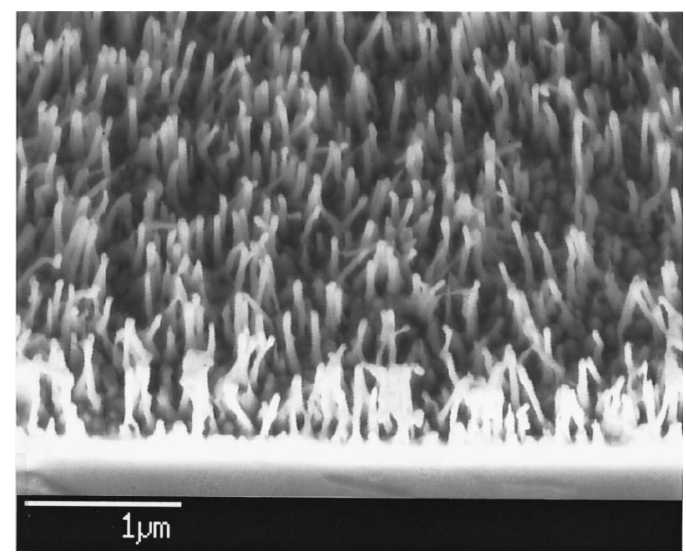

FIG. 4. SEM image of whiskers formed on defects during PEC etching of $\mathrm{N}$-polar heteroepitaxial GaN layer.

cations in Ga-polar heteroepitaxial layers. No other extended crystallographic defects have been found in this material.

Figure 2 shows an optical image of an as-grown N-polar GaN layer, exhibiting the characteristic hexagonal pyramidal or flat growth hillocks. The origin of the macroscopically flat hillocks is attributed to the operation of the individual or clustered dislocations, ${ }^{20}$ while pyramidal, sometimes top-flat hillocks contain central IDs. ${ }^{21-24}$ Cross-sectional TEM examination of as-grown samples showed the presence of a more complex dislocation structure than that of Ga-polar material, see Fig. 3. In addition, a high density of IDs nucleated at the sapphire/GaN interface and threading to the top of the layer has been recorded. PEC etching under the same conditions as used for Ga-polar material reveals coexisting straight and bent whiskers, as shown in Fig. 4. Detailed TEM examination of specimens, prepared after PEC etching, using different diffraction conditions, confirmed the association of straight whiskers with IDs and straight or bent whiskers with dislocations, as illustrated in Figs. 5(a) and 5(b), respectively. A HRTEM image of one whisker formed on an ID, which is representative for the whole population of IDs, is shown in Fig. 6. It demonstrates that IDs of about $20 \mathrm{~nm}$ diam are embedded in a residual $\mathrm{N}$-polar $\mathrm{GaN}$ to form whiskers of diameter up to $60 \mathrm{~nm}$. This means that around the defects [both dislocations (Figs. 1 and 5(b) and IDs (Figs. 5(a) and 6)] there is a $20-25$-nm-thick zone of matrix which is not etched. Surprisingly, IDs of larger diameter (above $100 \mathrm{~nm}$ ) are etched much more rapidly than the surrounding $\mathrm{N}$-polar matrix, see Fig. 7(a), which is opposite to the result of etching in "orthodox" etchants. ${ }^{25}$ It is important to note that though the ID itself is etched more quickly, the inversion domain boundary (IDB) is protruding above the surrounding N-polar matrix, i.e., it is resistant to PEC etching. Similarly, inside the etched "crater" numerous whiskers are often formed, indicating the presence of dislocations inside the IDs. In addition to the large diameter ID situated in the center of the hexagonal growth hillock of Fig. 7(a), one smaller diameter ID (marked by an arrow) has been quickly etched. Many such ID-related etch craters, with diameter ranging from about $100 \mathrm{~nm}$ up to $1 \mu \mathrm{m}$, and randomly distributed over the etched samples, have been observed. Clearly the threshold diameter of IDs, which "open" during PEC etch-
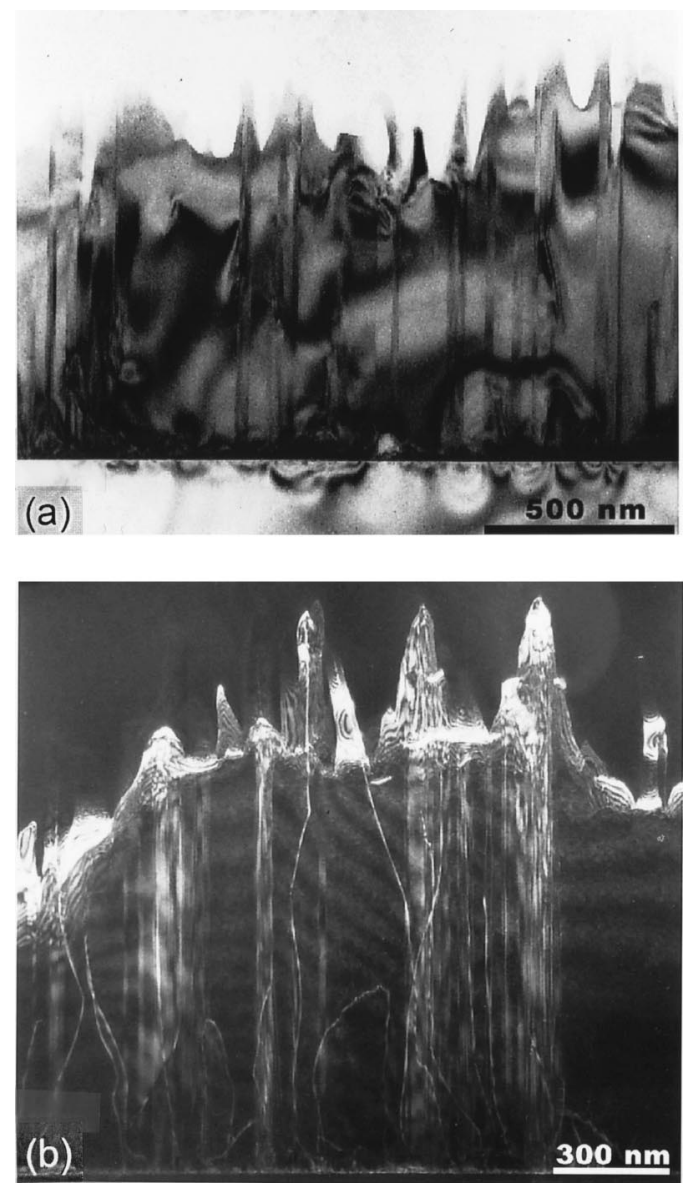

FIG. 5. Cross-sectional TEM images of N-polar GaN heteroepitaxial layer showing correlatin between PEC etched whiskers and (a) IDs and (b) dislocations.

ing, is above $60 \mathrm{~nm}$ (the average diameter of whiskers) and below $100 \mathrm{~nm}$.

The formation of whiskers on dislocations during PEC etching of $\mathrm{GaN}$ can be explained by the recombinative properties of these defects, as suggested by Youtsey, Romano, and Adesida. ${ }^{8}$ There are numerous experimental indications and theoretical predictions, which demonstrate electrical (recombinative or nonradiative) properties of dislocations in GaN. ${ }^{26-32}$ Previous studies on electroless photoetching of GaAs (Refs. 4, 6, and 33) also justify this conclusion. Properties of IDBs in GaN, on the other hand, are still not well understood. Based on the HRTEM studies and image simulation technique, different models for IDB structures have been analyzed (see, e.g., Refs. 34-37). On the basis of models it was suggested that IDBs in GaN should be electrically inactive. ${ }^{37,38}$ Theoretical calculations of binding (formation) energies of native defects indicate, however, a preference for these defects to form or to be trapped at the planar defects, which might successively induce deep states and alter the electrical properties. ${ }^{38,39}$ Experimental results presented in this article provide strong evidence for the electrical activity of IDBs in GaN: during PEC etching of the N-polar matrix containing large-diameter Ga-polar IDs [Fig. 7(a)], IDBs are etched most slowly, i.e., they must serve as very effective recombination defects for photogenerated carriers (holes). When the diameter of an ID is smaller than twice the thick- 


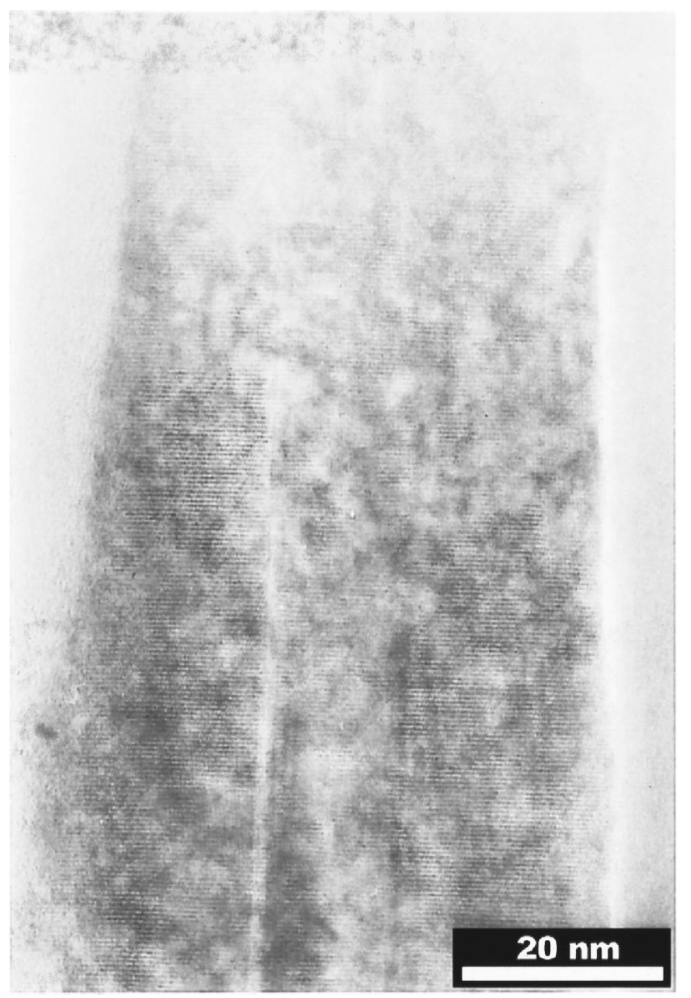

FIG. 6. Cross-sectional [10-10] HRTEM image of a PEC etched whisker formed on an ID in N-polar GaN heteroepitaxial layer.

ness of the material in the vicinity of the IDB (which is not etched due to depletion of carriers), then the whole Ga-polar ID is not etched [Figs. 5(a) and 6]. This does not indicate, however, that the ID as a whole constitutes a recombinative defect. It becomes evident when IDs of larger diameter are photoetched: the Ga-polar inner part of the defects is etched fastest. This phenomenon can be explained by taking into account preferential incorporation of impurities/dopants (such as silicon and oxygen) on the N-polar surface as compared to the Ga polar surface during MOCVD growth. ${ }^{40,41}$ As a result, the N-polar matrix is characterized by a higher carrier concentration, (say, $n^{+}$) versus the Ga-polar ID (say, $n$ ). During simultaneous electroless photoetching of such an $n / n^{+}$system, $n^{+}$regions are etched much slower than $n$ regions due to narrower space charge region width $\left(W_{\mathrm{sc}} \sim 1 / n^{1 / 2}\right), \quad$ as was quantitatively determined for GaAs. ${ }^{33,42}$ The effect is pronounced in GaN and clearly demonstrates the difference in the mechanism of defect-selective electroless and orthodox etching. In order to confirm this difference, part of the N-polar sample used in this study has been etched in a phosphoric/sulphuric acid mixture (labeled $\mathrm{HH}=3: 1$ after Ref. 25). The whole large-diameter Ga-polar IDs appeared to be resistance to the etchant, while pronounced attack of the surrounding N-polar matrix occurred, see Fig. 7(b). Apparently, in this orthodox etching system, orientation-dependent anisotropy of the properties of Ga- and $\mathrm{N}$-polar surfaces is responsible for the differentiation of the etch rates at IDs versus the matrix. This anisotropy can be expressed in terms of a different surface potential on Gapolar IDs embedded in a N-polar GaN matrix, as was recently shown using surface-potential electric-force
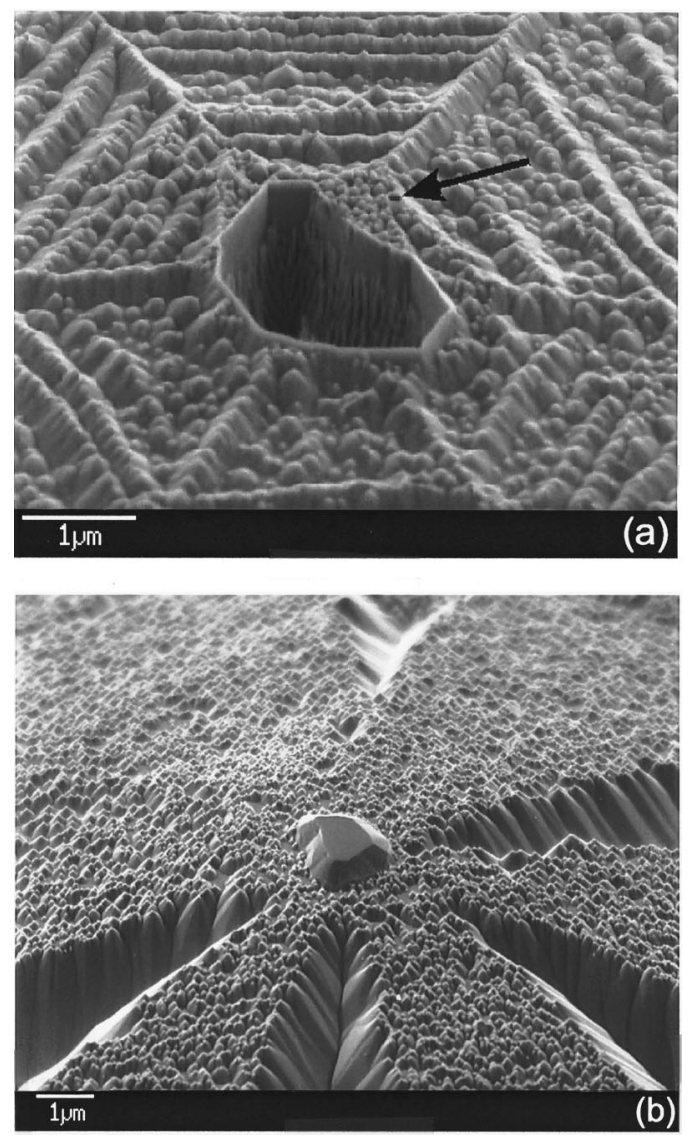

FIG. 7. SEM images of the central parts of hexagonal growth pyramids on N-polar heteroepitaxial GaN layer after (a) PEC etching and (b) HH etching.

microscopy. ${ }^{43}$ While the Ga-polar (0001) surface of the ID from Fig. 7(b) is not etched in the $\mathrm{HH}$ mixture, striking dissolution occurs at the edges of the ID and also at the corners of the hexagonal growth pyramid. This is exactly the opposite to the relative dissolution rates at the same structural features during PEC etching [compare Fig. 7(a) and 7(b)]. The enhanced rate in the orthodox etchant at these sites can be attributed to the increased impurity level: at IDBs due to the possible formation or trapping of native defects (as discussed above) and at the corners of the pyramid due to the accumulation of point defects at the meeting area of the growth steps (which in atomic scale move horizontally according to the kinking mechanism). Consequently, it could be deduced that the latter features also have recombinative properties because they form pronounced ridges during PEC etching, see Fig. 7(a).

\section{SUMMARY}

In conclusion, experimental results indicate that PEC etching of $\mathrm{GaN}$ in aqueous $\mathrm{KOH}$ solutions is similar to electroless photoetching of other III-V semiconductors (e.g., $\mathrm{GaAs}$ in the $\mathrm{CrO}_{3}-\mathrm{HF}-\mathrm{H}_{2} \mathrm{O}$ etching system). As a consequence of the critical involvement of photogenerated carriers in the mechanism of dissolution of GaN during PEC etching, recombinative defects are etched more slowly than the defect-free matrix. It has been shown by TEM calibration that apart from dislocations, IDs are revealed by this method. 
From PEC etching of IDs of different diameters (in the range $20 \mathrm{~nm}$ up to $2 \mu \mathrm{m}$ ) in N-polar heteroepitaxial GaN layers it is concluded that IDBs are electrically active defects. Remarkable differences in PEC etch rate on large-size IDs and on the N-polar matrix are explained in terms of the different widths of the space-charge region that is influenced by the level of carrier concentration.

\section{ACKNOWLEDGMENTS}

The authors gratefully acknowledge the critical reading of the manuscript by J. J. Kelly. This work has been financially supported by Stichting voor Fundamenteel Onderzoek der Materie (FOM). One of the authors (J.L.W.) wishes to thank NATO for a Linkage Grant.

${ }^{1}$ J. L. Weyher and J. L. Giling, J. Appl. Phys. 58, 219 (1985).

${ }^{2}$ E. D. Bourret, A. G. Elliot, B.-T. Lee, and J. M. Jaklevic, in Proc. Defect Recognition and Image Processing in III-V Compounds II, Monterey 1987, edited by E. R. Weber (Elsevier, Amsterdam, 1987), p. 95.

${ }^{3}$ J. L. Weyher, R. Fornari, T. Görög, J. J. Kelly, and B. Erné, J. Cryst. Growth 141, 57 (1994).

${ }^{4}$ J. L. Weyher, Inst. Phys. Conf. Ser. 146, 399 (1995).

${ }^{5}$ J. L. Weyher, Inst. Phys. Conf. Ser. 160, 199 (1997).

${ }^{6}$ P. H. L. Notten, J. E. A. M. van den Meerakker, and J. J. Kelly, Etching of III-V Semiconductors: An Electrochemical Approach (Elsevier Science, Amsterdam, 1991).

${ }^{7}$ J. van de Ven, J. L. Weyher, J. E. A. M. van den Meerakker, and J. J. Kelly, J. Electrochem. Soc. 133, 799 (1986).

${ }^{8}$ C. Youtsey, L. T. Romano, and I. Adesida, Appl. Phys. Lett. 73, 797 (1998).

${ }^{9}$ C. Youtsey, L. T. Romano, R. J. Molnar, and I. Adesida, Appl. Phys. Lett. 74, 3537 (1999).

${ }^{10}$ A. Watanabe, H. Takahashi, T. Tanaka, H. Ota, K. Chikuma, H. Amano, T. Kashima, R. Nakamura, and I. Akasaki, Jpn. J. Appl. Phys., Part 2 38, L1159 (1999).

${ }^{11}$ P. Visconti, K. M. Jones, M. A. Reshchikov, R. Cingolani, and H. Markoç, Appl. Phys. Lett. 77, 3532 (2000).

${ }^{12}$ C. Youtsey, I. Adesida, and G. Bulman, Appl. Phys. Lett. 71, 2151 (1997).

${ }^{13}$ D. A. Stocker and E. F. Schubert, J. Electrochem. Soc. 146, 2702 (1999).

${ }^{14}$ I. M. Huygens, K. Strubbe, and W. P. Gomes, J. Electrochem. Soc. 147, 1797 (2000).

${ }^{15}$ T. Rotter, D. Mistele, J. Stemmer, F. Fedler, J. Aderhold, J. Graul, V. Schwegler, C. Kirchner, M. Kamp, and M. Heuken, Appl. Phys. Lett. 76, 3923 (2000).

${ }^{16}$ G. Nowak, X. H. Xia, J. J. Kelly, J. L. Weyher, and S. Porowski, J. Cryst. Growth 222, 735 (2001).

${ }^{17}$ F. K. de Theije, A. R. A. Zauner, P. R. Hageman, W. J. P. van Enckevort, and P. K. Larsen, J. Cryst. Growth 197, 37 (1999).

${ }^{18}$ J. L. Rouviere, J. L. Weyher, M. Seelmann-Eggebert, and S. Porowski, Appl. Phys. Lett. 73, 668 (1998).
${ }^{19}$ H. W. Zandbergen, J. Jansen, A. R. A. Zauner, and J. L. Weyher, J. Cryst. Growth 210, 167 (2000).

${ }^{20}$ G. Nowak, K. Pakula, I. Grzegory, J. L. Weyher, and S. Porowski, Phys. Status Solidi B 216, 649 (1999).

${ }^{21}$ J. L. Rouviere, M. Arlery, R. Niebuhr, K. H. Bachem, and O. Briot, Mater. Sci. Eng., B B43, 161 (1997).

${ }^{22}$ L. T. Romano and T. H. Myers, Appl. Phys. Lett. 71, 3486 (1997).

${ }^{23}$ J. L. Weyher, P. D. Brown, A. R. A. Zauner, S. Müller, C. B. Boothroyd, D. T. Foord, P. R. Hageman, C. J. Humphreys, P. K. Larsen, I. Grzegory, and S. Porowski, J. Cryst. Growth 204, 419 (1999).

${ }^{24}$ V. Potin, P. Ruterana, and G. Nouet, Mater. Sci. Eng., B59, 173 (1999).

${ }^{25}$ J. L. Weyher, P. D. Brown, J. L. Rouviere, T. Wosinski, A. R. A. Zauner, and I. Grzegory, J. Cryst. Growth 210, 151 (2000).

${ }^{26}$ S. J. Rosner, E. C. Carr, M. J. Ludowise, G. Girolami, and H. I. Erikson, Appl. Phys. Lett. 70, 420 (1997).

${ }^{27}$ T. Sugahara, H. Sato, M. Hao, Y. Naoi, S. Kurai, S. Tottori, K. Yamashita, K. Nishino, L. T. Romano, and S. Sakai, Jpn. J. Appl. Phys., Part 2 37, L398 (1998).

${ }^{28}$ D. C. Look, Z. Fang, and L. Polenta, MRS Internet J. Nitride Semicond. Res. 5S1, W10.5 (2000).

${ }^{29}$ K. Leung, A. F. Wright, and E. B. Stechel, Appl. Phys. Lett. 74, 2495 (1999).

${ }^{30}$ P. Hacke, K. Domen, A. Kuramata, T. Tanahashi, and O. Ueda, Appl. Phys. Lett. 76, 2547 (2000).

${ }^{31}$ N. Grandjean, J. Massies, I. Grzegory, and S. Porowski, Semicond. Sci. Technol. 16, 358 (2001).

${ }^{32}$ S. Dassonneville, A. Amokrane, B. Sieber, J.-L. Farvacque, B. Beaumont, and P. Gibart, J. Appl. Phys. 89, 3736 (2001).

${ }^{33}$ C. Frigeri, J. L. Weyher, J. Jimenez, and P. Martin, J. Phys. III 7, 2339 (1997).

${ }^{34}$ L. T. Romano, J. E. Northrup, and M. A. O’Keefe, Appl. Phys. Lett. 69, 2394 (1996)

${ }^{35}$ J.-L. Rouviere, M. Arlery, and A. Bourret, Inst. Phys. Conf. Ser. 157, 173 (1997).

${ }^{36}$ V. Potin, P. Ruterana, G. Nouet, A. Salvador, and H. Markoc, Mater. Res. Soc. Symp. Proc. 468, 323 (1997).

${ }^{37}$ D. Cherns, W. T. Young, M. A. Saunders, F. A. Ponce, and S. Nakamura, Inst. Phys. Conf. Ser. 157, 187 (1997).

${ }^{38} \mathrm{~J}$. Elsner, Th. Frauenheim, M. Haugk, R. Gutierrez, R. Jones, and M. I. Heggie, Mater. Res. Soc. Symp. Proc. G3, $29 / 7$ (1999).

${ }^{39}$ J. A. Chisholm and P. D. Bristowe, MRS Internet J. Nitride Semicond. Res. 5S1, W3.72 (2000).

${ }^{40}$ P. Prystawko, M. Leszczynski, B. Beaumont, P. Gibart, E. Frayssinet, W. Knap, P. Wisniewski, M. Bockowski, T. Suski, and S. Porowski, Phys. Status Solidi B 210, 437 (1998).

${ }^{41}$ M. Mayer, A. Pelzmann, H. Y. Chung, M. Kamp, and K. J. Ebeling, J. Cryst. Growth 201/202, 318 (1999).

${ }^{42}$ C. Frigeri, J. L. Weyher, and L. Zanotti, J. Electrochem. Soc. 136, 262 (1989).

${ }^{43}$ K. M. Jones, P. Visconti, F. Yun, A. A. Baski, and H. Markoc, Appl. Phys. Lett. 78, 2497 (2001). 